\title{
Long-term functional health status and exercise test variables for patients with pulmonary atresia with intact ventricular septum: A Congenital Heart Surgeons Society study
}

Tara Karamlou, MD, MSc, ${ }^{a}$ Jeffrey A. Poynter, MD, ${ }^{\mathrm{b}}$ Henry L. Walters III, MD, ${ }^{\mathrm{c}}$ Jonathan Rhodes, MD, ${ }^{\mathrm{d}}$ Igor Bondarenko, MD, ${ }^{\mathrm{c}}$ Sara K. Pasquali, MD, ${ }^{\mathrm{e}}$ Stephanie M. Fuller, MD, ${ }^{\mathrm{f}}$ Linda M. Lambert, RN, ${ }^{\mathrm{g}}$ Eugene H. Blackstone, MD, ${ }^{\mathrm{h}}$ Marshall L. Jacobs, MD, ${ }^{\mathrm{i}}$ Kim Duncan, MD, ${ }^{\mathrm{j}}$ Christopher A. Caldarone, MD, ${ }^{\mathrm{b}}$ William G. Williams, MD, ${ }^{\mathrm{b}}$ and Brian W. McCrindle, MD, $\mathrm{MPH}^{\mathrm{k}}$

Background: A bias favoring biventricular (BV) repair exists regarding choice of repair pathway for patients with pulmonary atresia with intact ventricular septum (PAIVS). We sought to determine the implications of moving borderline candidates down a BV route in terms of late functional health status (FHS) and exercise capacity (EC).

Methods: Between 1987 and 1997, 448 neonates with PAIVS were enrolled in a multi-institutional study. Late EC and FHS were assessed following repair (mean 14 years) using standardized exercise testing and 3 validated FHS instruments. Relationships between FHS, EC, morphology, and 3 end states (ie, BV, univentricular [UV], or 1.5 -ventricle repair $[1.5 \mathrm{~V}])$ were evaluated.

Results: One hundred two of 271 end state survivors participated (63 BV, 25 UV, and 14 1.5V). Participants had lower FHS scores in domains of physical functioning $(P<.001)$ compared with age- and sex-matched normal controls, but scored significantly higher in nearly all psychosocial domains. EC was higher in $1.5 \mathrm{~V}$-repair patients $(P=.02)$, whereas discrete FHS measures were higher in BV-repair patients. Peak oxygen consumption was low across all groups, and was positively correlated with larger initial tricuspid valve $z$-score $(P<.001)$, with an enhanced effect within the BV-repair group.

Conclusions: Late patient-perceived physical FHS and measured EC are reduced, regardless of PAIVS repair pathway, with an important dichotomy whereby patients with PAIVS believe they are doing well despite important physical impediments. For those with smaller initial tricuspid valve $z$-score, achievement of survival with $\mathrm{BV}$ repair may be at a cost of late deficits in exercise capacity, emphasizing that better outcomes may be achieved for borderline patients with a 1.5V- or UV-repair strategy. (J Thorac Cardiovasc Surg 2013;145:1018-27)

From the Division of Pediatric Cardiac Surgery, ${ }^{a}$ Benioff Children's Hospital, University of California, San Francisco, San Francisco, Calif; Division of Cardiovascular Surgery, ${ }^{\mathrm{b}}$ The Hospital For Sick Children and the University of Toronto, Toronto, Ontario, Canada; Department of Cardiovascular Surgery, ${ }^{\mathrm{c}}$ Children's Hospital of Michigan, Detroit, Mich; Department of Cardiology, ${ }^{\mathrm{d}}$ Children's Hospital, Boston, Mass; Division of Cardiology, ${ }^{\mathrm{e}}$ Department of Pediatrics and Communicable Diseases, C.S. Mott Children's Hospital, University of Michigan, Ann Arbor, Mich; Division of Cardiovascular Surgery, ${ }^{\mathrm{f}}$ The Children's Hospital of Philadelphia, Philadelphia, Pa; Department of Pediatric Cardiovascular Surgery, ${ }^{\mathrm{g}}$ Primary Children's Hospital, Salt Lake City, Utah; Department of Quantitative Health Sciences, ${ }^{\text {h }}$ Research Institute, and Department of Pediatric and Congenital Heart Surgery, Cleveland Clinic, Cleveland, Ohio; Division of Cardiothoracic Surgery, ${ }^{\mathrm{j}}$ Children's Hospital and Medical Center, Omaha, Neb; and Division of Cardiology, ${ }^{\mathrm{k}}$ The Hospital for Sick Children, Toronto, Ontario, Canada.

Grant support was provided by the Children's Heart Foundation.

Disclosures: Authors have nothing to disclose with regard to commercial support.

Read at the 92nd Annual Meeting of The American Association for Thoracic Surgery, San Francisco, California, April 28-May 2, 2012.

Received for publication April 24, 2012; revisions received Oct 18, 2012; accepted for publication Nov 6, 2012; available ahead of print Jan 31, 2013.

Address for reprints: Tara Karamlou, MD, MSc, Division of Pediatric Cardiac Surgery, Benioff Children's Hospital, University of California, San Francisco, 513 Parnassus Ave, Suite S-549, San Francisco, CA 94506 (E-mail: tara. karamlou@ucsfmedctr.org).

0022-5223/\$36.00

Copyright (c) 2013 by The American Association for Thoracic Surgery

http://dx.doi.org/10.1016/j.jtcvs.2012.11.092
$\mathcal{B}$ Supplemental material is available online.

Pulmonary atresia with intact ventricular septum (PAIVS) has a broad morphologic spectrum hinging in large part on the degree of hypoplasia of right heart structures. The Congenital Heart Surgeons Society (CHSS) has previously shown $^{1,2}$ that a balanced approach, including selective application of both biventricular (BV) and univentricular (UV) repairs based on the initial tricuspid valve $z$-score (ITVZ), which is a surrogate measure of right-sided hypoplasia, is associated with the highest rates of survival and achievement of definitive repair. Nonetheless, a bias exists favoring BV repair in many institutions predicated on the assumption that BV physiology maximizes long-term functional health status (FHS) and exercise performance. Our prior investigations ${ }^{1,2}$ did not consider the influence of final end state on late FHS outcomes or late exercise capacity (EC). The question remains, therefore: If one forces a borderline candidate down a BV-repair pathway 


$$
\begin{aligned}
& \text { Abbreviations and Acronyms } \\
& \begin{aligned}
1.5 \mathrm{~V} & =1.5 \text { ventricle } \\
\mathrm{BV} & =\text { biventricular } \\
\mathrm{CHQ} & =\text { Child Health Questionnaire } \\
\mathrm{CHSS} & =\text { Congenital Heart Surgeons Society } \\
\mathrm{EC} & =\text { exercise capacity } \\
\mathrm{FHS} & =\text { functional health status } \\
\mathrm{ITVZ} & =\text { initial tricuspid valve } z \text {-score } \\
\text { PEDSQL } & =\text { Pediatric Quality of Life Inventory } \\
\mathrm{RV} & =\text { Right ventricle } \\
\mathrm{UV} & =\text { univentricular } \\
\mathrm{VO} 2 & =\text { oxygen consumption }
\end{aligned}
\end{aligned}
$$

and achieves survival, what are the implications in terms of long-term FHS and quality of life? To address this question, the CHSS undertook a multicenter cross-sectional study of surviving patients with PAIVS to determine if BV repair was associated with a late ( $\geq 10$ years) benefit in terms of FHS and EC relative to UV or 1.5-ventricle (1.5V) repair.

\section{METHODS \\ Patients}

Between 1987 and 1997, 448 neonates with functional PAIVS admitted to a CHSS institution within 30 days of birth were prospectively enrolled in a multi-institutional study. ${ }^{1,2}$ Neonates were managed according to institutional preference. Median enrollment across the 33 participating institutions was 12 neonates per institution (range, 1-44 neonates). Morphologic data were obtained by means of independent review of preintervention echocardiograms and catheterization results, as previously described, ${ }^{1,2}$ with differences between right ventricular (RV) fistulae and RV sinusoids adjudicated by a senior cardiologist following review. ${ }^{1,2}$ For this investigation, we defined those patients who at most recent follow-up had 2 functional ventricles and in-series pulmonary and systemic circulations, without systemic-to-arterial shunts or cavopulmonary connection, to have achieved $\mathrm{BV}$ repair regardless of the status of the atrial septum. Patients with antegrade pulmonary blood flow and a cavopulmonary shunt formed the $1.5 \mathrm{~V}$-repair group. The UV-repair group was composed of patients who had undergone the Fontan procedure. Although our initial investigations ${ }^{1,2}$ considered only what was believed to be true pulmonary atresia, the rationale for the inclusion criteria of functional pulmonary atresia in this investigation is provided in Appendix E1. The CHSS data center maintains annual follow-up of this cohort, with a current total of $271(62 \%)$ survivors. Annual follow-up included $32 \%(n=86)$ of the cohort in 2011 and $73 \%(\mathrm{n}=197)$ within the past 5 years. All surviving patients from this initial cohort were approached to participate in this crosssectional study. All participating centers obtained local institutional review board or ethics committee approval before initiating the study and written informed consent or assent was obtained for all subjects.

\section{Exercise Testing}

Standardized cardiopulmonary exercise testing was prospectively performed according to the protocols developed by Paridon and colleagues. ${ }^{3-5}$ Summary and graphic data from the metabolic measurements, electrocardiographic measurements, and pulse oximetry were forwarded to the data center. In addition, all breath-by-breath metabolic data averaged over 20-second intervals and electrocardiograms were forwarded to the CHSS data center. The data were reviewed for quality and measurements made as described previously in the Pediatric Heart Network Fontan Cross-Sectional Study. ${ }^{5-9}$

\section{Functional Status Questionnaires}

To assess FHS, the study used 3 standardized survey instruments or questionnaires: the Child Health Questionnaire (CHQ) child report form, the teen report and young adult report forms of the Pediatric Quality of Life Inventory 4.0 (PedsQL), and the Congenital Heart Adolescent and Teenager Questionnaire. Questionnaires were administered either at the time of a clinic visit to the CHSS member institution, or by mail with telephone proctor. Ideally, the questionnaires were completed concomitant with exercise testing, but for subjects for whom this was not possible, questionnaires were completed and returned by mail within 3 months of exercise testing. The Hollingshead Four Factor Index of Social Status was administered concurrent with all questionnaires to adjust for the potential effect of socioeconomic status on FHS. ${ }^{10,11}$ Details regarding each instrument are related in Appendix E1.

\section{Statistical Analysis}

Data are described as frequencies, medians with ranges, or means with standard deviations. ITVZ scores were derived using the method of Rowlatt and colleagues, ${ }^{12}$ with informative imputation, when sufficient information was available, used for missing values. Patients in whom ITVZ score was missing following imputation $(n=9)$ were excluded from multivariable models. Scores (either from questionnaires or exercise tests) were related to initial morphologic features and other patient variables using multivariable generalized linear models, with a separate model for each discrete score. A comprehensive set of variable transformations were explored to optimize relationships and model performance. Analysis of each testing data set (score) was initially performed with all testing variables included to determine the overall $R^{2}$ adjusted for the number of included variables. Stepwise selection was then applied to guide final model selection, with $P<.15$ used for inclusion into the final model. Because not all tests were performed in all patients (Figure 1), analyses were restricted to individual test data sets, and no overall analysis incorporating all tests was performed. Particular focus was given to evaluating the relationship of scores to final end state (BV, UV, and $1.5 \mathrm{~V})$, with the end state modeled as an independent variable. Patients undergoing palliation without definitive repair and those undergoing heart transplant were not included in the multivariable models due to inadequate sample size. Correlations among exercise testing results and FHS scores were sought using general linear models and correlational analysis. Because this study involved evaluation of both subjective measures and objective measures, we performed a multivariate analysis using 4 selected outcome measures (percent predicted of normal for maximum oxygen consumption [VO2] and maximum heart rate, Physical Functioning Summary Score from the PedsQL, and Global General Health score from the CHQ) as simultaneous dependent variables to further explore the simultaneous influence of final end state and evaluate the amount of variation explained by each discrete measure. Response bias was sought by comparing categorical data for responders versus nonresponders using $\chi^{2}$ or Fisher exact test where appropriate, or by comparing continuous data for responders versus nonresponders using $t$ tests. Analyses were performed using SAS statistical software version 9.2 (SAS Institute, Cary, NC).

\section{RESULTS}

\section{Status of the Cohort: Achievement of End States and Survival}

During the study interval, 448 neonates were enrolled. Of these, 433 underwent surgery and 15 underwent no cardiac surgical intervention. Survival status and current end states of the survivors and the study participants are shown in 


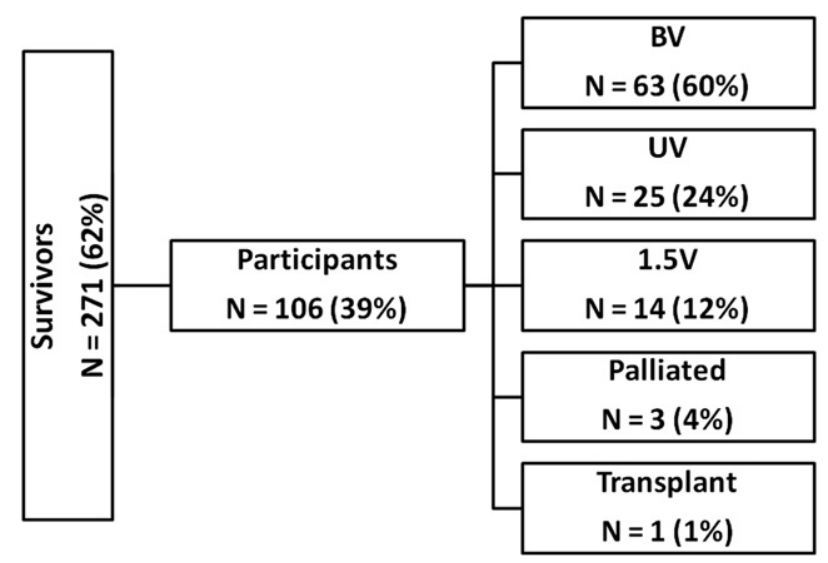

FIGURE 1. Flowchart depicting cross-sectional study participants segregated by current end state. $B V$, Biventricular repair; $U V$, univentricular repair; $1.5 \mathrm{~V}, 1.5$-ventricle repair.

Figure 1 and Figure E1. Importantly, 155 patients who underwent initial palliation have not reached an end state defined in this study, and 33 of these patients remain in a palliated state (see Figure E1).

\section{Study Participation and Patient Characteristics}

Of the 271 survivors, 106 (39\%) participated in the crosssectional study (Figure 1). For participants who have reached 1 of the 3 end states, the median interval from repair (ie, an operation that resulted in achievement of an end state) to completion of the questionnaires was 14.7 years (range, 3.5-21.8 years), with a median age of 18.6 years (range, 9.1-23.7 years). A majority of participants had reached BV repair, with correspondingly fewer patients in the UV and $1.5 \mathrm{~V}$ groups. Completion rates for the different instruments include $77 \%$ for exercise testing $(n=82), 68 \%$ for CHQ $(n=72), 63 \%$ for PedsQL $(n=67)$, and $67 \%$ for Congenital Heart Adolescent and Teenager Questionnaire $(\mathrm{n}=71)$. The Hollingshead Four Factor Score was completed by $54 \%(n=57)$. Initial morphologic characteristics (including ITVZ, RV size, prevalence of RV fistulae, and sinusoids) for participants were similar to nonparticipating survivors from the inception cohort, except that participants had a lower prevalence of RV-dependent coronary circulation ( 1 out of $106[1 \%]$ vs 10 out of $165[6 \%] ; P=.03$ ). Initial morphologic characteristics for participants segregated by the end state group are shown in Table 1. Not surprisingly, measures consistent with more severe degrees of right-sided hypoplasia were significantly more prevalent among the UV-repair group.

\section{Functional Status Results: Comparison With Normal Controls}

Important differences existed between published normative data and the PAIVS cohort as a whole regarding perceived FHS (see Table 2 and Figure E2, $A$ and $B$ ). We noted that patients with PAIVS had lower physical functioning scores on both the CHQ and the PedsQL than age- and sex-matched normal subjects. However, patients with PAIVS had higher scores than normal subjects on the CHQ in nearly all psychosocial domains.

\section{Influence of Repair Pathway on FHS Results}

The influence of repair pathway on FHS scores is shown in Table 2 and Figure 2, $A$. In general, age- and sex-adjusted scores were lower in UV-repair patients compared with BV-repair patients, although statistically significant FHS differences were limited to discrete domains within the CHQ. Based on the correlation analysis, the CHQ explained a much greater proportion of the variation than either the PedsQL or the Congenital Heart Adolescent and Teenager Questionnaire.

\section{Influence of Repair Pathway on Exercise Testing Results}

Based on standardized late exercise testing among this cohort, age- and sex-adjusted percent predicted peak VO2 was lowest among UV-repair patients (Table 2). However, based on our prior results with this cohort ${ }^{2}$ that related the importance of a morphologically driven protocol based on ITVZ in terms of optimizing survival and achievement of complete repair, we investigated peak $\mathrm{VO} 2$ across the spectrum of ITVZ scores. Peak VO2 was higher for those with larger ITVZ for all end state groups (see Figure 3, A)

TABLE 1. Participant characteristics $(\mathrm{N}=106)$

\begin{tabular}{|c|c|c|c|c|}
\hline Variable & Univentricular & Biventricular & $1.5 \mathrm{~V}$ & $P$ value* \\
\hline Age at repair (y) & $1.6(0.6$ to 16.6$)$ & 1.3 (Birth to 7.0 ) & 1.7 (Birth to 6.7) & .07 \\
\hline Age at evaluation (y) & $14.6(3.7$ to 17.9$)$ & 14.7 (7.0 to 21.8$)$ & 15.5 (4.6 to 17.8$)$ & .55 \\
\hline Birth weight $(\mathrm{kg})$ & $3.3 \pm 0.5$ & $3.5 \pm 0.4$ & $3.0 \pm 0.4$ & .11 \\
\hline Initial TV $z$-score & $-3.4(-4.9$ to 0.3$) \dagger$ & $-1.0(-3.6$ to 0.9$) \dagger$ & $-2.3(-4.1$ to -0.3$)$ & $<.001$ \\
\hline Initial RVSP (mm Hg) & $122 \pm 34$ & $110 \pm 22 \ddagger$ & $130 \pm 26$ & .04 \\
\hline RV sinusoids (N [\%]) & $20(87 \%)$ & $11(19 \%)$ & $5(42 \%)$ & $<.001$ \\
\hline RV dependent $\mathrm{CC}(\mathrm{N}[\%])$ & $1(1 \%)$ & $0(0 \%)$ & $0(0 \%)$ & .24 \\
\hline RV fistulas $(\mathrm{N}[\%])$ & $14(56 \%)$ & $4(6 \%)$ & $4(29 \%)$ & $<.001$ \\
\hline
\end{tabular}

Values are medians with ranges, or mean \pm standard deviation. $1.5 V, 1.5$-ventricle; $T V$, tricuspid valve; $R V S P$, right ventricular systolic pressure; $R V$, right ventricle; $C C$, coronary circulation. *Overall $P$ value among end states. $\dagger P<.01$ compared with reference group (ie, $1.5 \mathrm{~V}$-repair group). $\ddagger P<.05$ compared with reference group (ie, $1.5 \mathrm{~V}$-repair group). 
TABLE 2. Exercise testing and functional health status results for pulmonary atresia with intact ventricular septum (PAIVS) cohort compared with published normative data followed by results segregated by the 3 specified end states

\begin{tabular}{|c|c|c|c|c|c|c|c|}
\hline \multirow[b]{3}{*}{ CHQ } & \multicolumn{3}{|c|}{ Published normative data } & \multicolumn{4}{|c|}{ Study-specified end states } \\
\hline & Normal subjects & Overall PAIVS & & UV & BV & $1.5 \mathrm{~V}$ & verall \\
\hline & $(\mathbf{N}=2361)$ & $\mathbf{N}=\mathbf{7 0}$ & $P$ value & $\mathbf{N}=16$ & $\mathbf{N}=\mathbf{4 5}$ & $\mathbf{N}=\mathbf{9}$ & $P$ value* \\
\hline Global general health & NA & $80.66 \pm 19.89$ & NA & $79.33 \pm 19.07$ (79.46) & $84.26 \pm 13.42(84.24) \dagger$ & $65.55 \pm 32.25(65.13)$ & .05 \\
\hline Physical functioning & $94.79 \pm 9.59$ & $85.13 \pm 16.54$ & $<.001$ & $84.25 \pm 13.42(84.26)$ & $85.61 \pm 14.47(85.62)$ & $84.32 \pm 29.33(84.27)$ & .99 \\
\hline Role social-emotional & $88.51 \pm 18.54$ & $93.24 \pm 16.74$ & .03 & $95.83 \pm 16.67(96.00)$ & $93.33 \pm 14.68(93.39)$ & $87.50 \pm 26.85(86.87)$ & .80 \\
\hline Role social-behavioral & $92.73 \pm 15.94$ & $95.97 \pm 11.90$ & .08 & $95.14 \pm 16.71(95.32)$ & $96.04 \pm 10.64(96.07)$ & $97.22 \pm 7.86(96.76)$ & .85 \\
\hline Role social-physical & $94.58 \pm 14.79$ & $93.72 \pm 17.82$ & .64 & $95.83 \pm 16.67(95.93) \ddagger$ & $95.55 \pm 11.46(95.60) \ddagger$ & $79.17 \pm 37.30(78.70)$ & .18 \\
\hline Bodily pain & $72.8 \pm 20.82$ & $88.04 \pm 16.82$ & $<.001$ & $87.69 \pm 20.48(88.04)$ & $88.52 \pm 14.86(88.46)$ & $88.67 \pm 16.97(86.17)$ & .98 \\
\hline Behavior & $77.51 \pm 13.76$ & $81.52 \pm 21.85$ & .03 & $75.94 \pm 30.23(76.17)$ & $83.18 \pm 18.90(83.11)$ & $83.33 \pm 18.54(83.27)$ & .67 \\
\hline Self-esteem & $74.64 \pm 17.07$ & $80.84 \pm 15.51$ & .005 & $76.30 \pm 18.57(76.28)$ & $81.59 \pm 15.42(81.58)$ & $85.22 \pm 7.31(85.29)$ & .71 \\
\hline General health & $68.13 \pm 15.55$ & $66.38 \pm 16.55$ & .25 & $63.36 \pm 15.51(63.36)$ & $68.39 \pm 14.89(68.51)$ & $61.71 \pm 25.00(61.14)$ & .51 \\
\hline Family cohesion & $71.23 \pm 25.99$ & $76.00 \pm 23.28$ & .21 & $74.38 \pm 28.34(74.73)$ & $76.56 \pm 22.53(76.67)$ & $76.11 \pm 19.12(74.93)$ & .93 \\
\hline
\end{tabular}

\begin{tabular}{rrrrrr}
\hline PedsQL & $\mathbf{N}=67$ & $\mathbf{N}=64$ & $\mathbf{N}=14$ & $\mathbf{N}=41$ & $\mathbf{N}=9$
\end{tabular}

\begin{tabular}{llllllll}
\hline Physical Health Summary Score & $86.25 \pm 10.63$ & $79.85 \pm 17.24$ & .01 & $77.44 \pm 16.65(77.76)$ & $81.26 \pm 17.42(81.51)$ & $77.14 \pm 18.60(75.53)$ & .46
\end{tabular}

$\begin{array}{lllllll}\text { Psychosocial Health Summary } \quad 79.37 \pm 15.70 & 80.90 \pm 17.81 \quad .58 & 78.93 \pm 16.79(79.41) & 82.06 \pm 18.57(82.31) & 78.70 \pm 17.23(76.77) & .28\end{array}$ Score

\begin{tabular}{|c|c|c|c|c|c|c|}
\hline Exercise testing & & $\mathbf{N}=\mathbf{8 0}$ & $\mathbf{N}=\mathbf{2 2}$ & $\mathbf{N}=\mathbf{4 5}$ & $\mathbf{N}=\mathbf{1 3}$ & \\
\hline VO2 (\% predicted $)$ & NA & $73.10 \pm 15.44$ & $63.96 \pm 10.45(64.02) \ddagger$ & $75.78 \pm 15.98(75.76)$ & $77.88 \pm 15.37(77.88)$ & .02 \\
\hline Maximum heart rate $(\%$ predicted $)$ & NA & $82.20 \pm 15.61$ & $76.49 \pm 10.90(75.98) \ddagger$ & $83.11 \pm 17.91(83.32)$ & $88.40 \pm 10.25(88.49)$ & .18 \\
\hline
\end{tabular}

Values in parentheses represent age- and sex-adjusted regression estimates. $C H Q$, Child Health Questionnaire; NA, not applicable; Peds $Q L$, Pediatric Quality of Life Inventory version 4.0. VO2, oxygen consumption; $U V$, univentricular repair; $B V$, biventricular repair; $1.5 \mathrm{~V}, 1.5$-ventricle repair. *Overall difference among end states. $\dagger P<.01$ compared with reference group (ie, $1.5 \mathrm{~V}$-repair group). $\ddagger P<.05$ compared with reference group (ie, $1.5 \mathrm{~V}$-repair group).

$(P<.001)$. However, when investigating the relationship between peak VO2 and ITVZ within each end state group, there was a trend whereupon $\mathrm{BV}$ repair in patients with larger ITVZ had improved peak VO2 relative to the UVrepair group, although there were not enough overlapping data points to make statistical comparisons between the UV-repair and the BV-repair groups. Importantly, peak $\mathrm{VO} 2$ in the BV-repair group with low ITVZ scores $($ eg, $<-2)$, tended to be lower than peak VO2 in the 1.5ventricle group with comparable ITVZ scores, (Figure 3, B).

Maximum heart rate was below normal for all groups. Patients from the $1.5 \mathrm{~V}$-repair group were able to reach a significantly higher heart rate than the UV-repair group (Table 2). Unlike percent predicted peak VO2, no interaction between percent predicted maximum heart rate and ITVZ was observed (Figure E3).

Multivariable factors associated with exercise testing results and selected FHS domains are listed in Table E1. In addition to ITVZ, overall end state was also significantly associated with peak $\mathrm{VO} 2$, with the $\mathrm{BV}$-repair group faring worse than the $1.5 \mathrm{~V}$-repair group. The overall $R^{2}$ for the peak VO2 model was 0.58 , indicating that $58 \%$ of the variation in this measure was explained by the variables included. Figure E4 is a risk-adjusted nomogram across the spectrum of participant ages, and demonstrates 3 solutions for the multivariable peak $\mathrm{VO} 2$ equation for a hypothetical male patient with an ITVZ of -2 . Although peak VO2 increased with increasing age in all end state groups, the
$1.5 \mathrm{~V}$-repair group had improved peak VO2 compared with both the UV-repair and BV-repair groups, although this difference was significant only between the $1.5 \mathrm{~V}$-repair and BV-repair groups. Regarding percent predicted maximum heart rate, patients with BV repair tended to fare worse compared with the $1.5 \mathrm{~V}$-repair group $(P=.06)$, as did patients with RV fistulae $(P=.01)$ and important tricuspid valve incompetence $(P=.05)$. Socioeconomic status was associated with most FHS scores, and accounted for the majority of score variation. We did not find any independent factors associated with either the physical or psychosocial summary score evaluated by the PedsQL.

\section{Influence of Repair Pathway on Simultaneous FHS and EC Measures}

The multivariate analysis agreed with our initial analysis, in that it demonstrated a significant association of FHS with end state $(P=.006$ [Wilks' lambda]). The objective measures (exercise variables) had the greatest model effect and accounted for the majority of model variation compared with the subjective measures (FHS scores). The first eigenroot (corresponding to peak V02) explained $73 \%$ of the variation, and had the largest vector magnitude $(49 \%)$, with maximum heart rate being second, explaining $26 \%$ of the variation. FHS scores were much less important, with vector magnitudes of 0.09 and 0.03 for physical functioning summary score and global general health, respectively. 

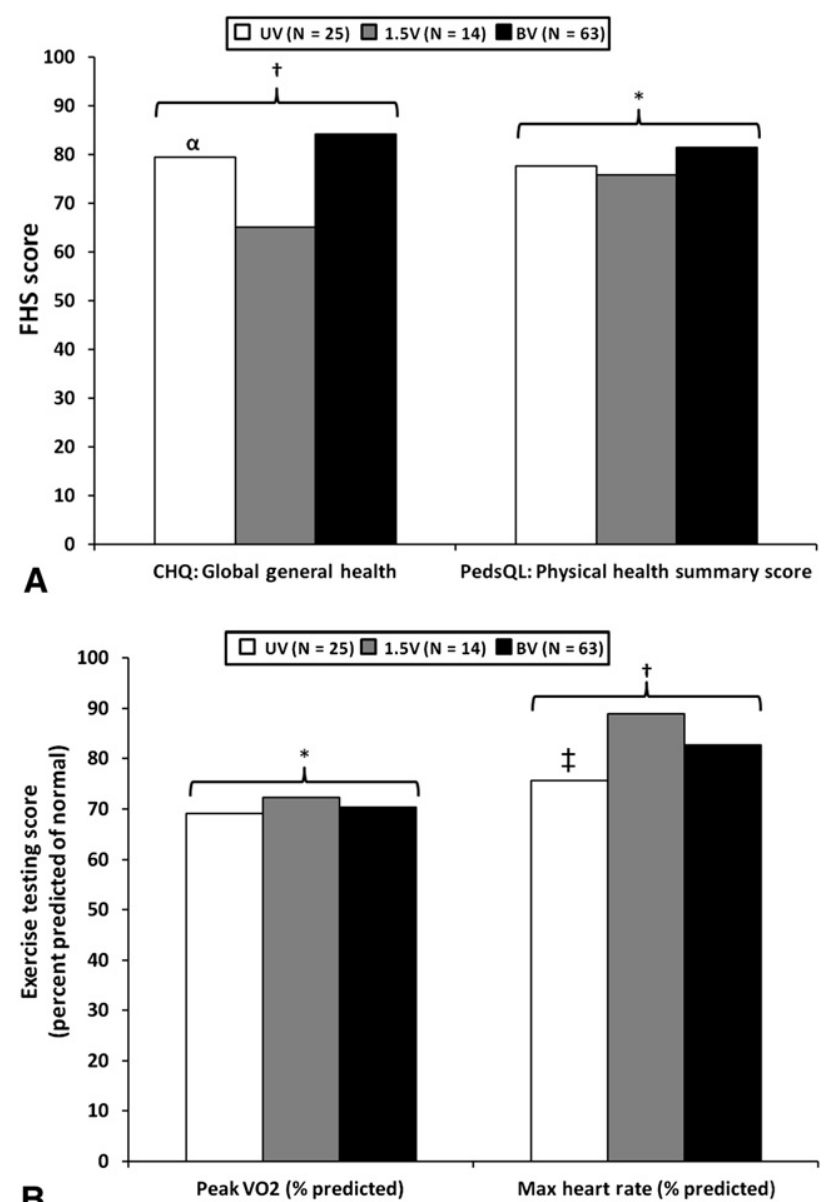

FIGURE 2. A, Influence of end state on selected functional health status (FHS) scores. This histogram demonstrates age- and sex-adjusted values for the 3 end state groups in selected domains. In general, age- and sexadjusted FHS measures were similar in patients undergoing univentricular $(U V)$ repair compared with patients undergoing biventricular $(B V)$ repair. $\mathrm{B}$, Histogram depicting influence of repair pathway on exercise test results. Age- and sex-adjusted means for percent predicted peak oxygen consumption (VO2) and maximum heart rate (Max heart rate). The BV group had lower peak $\mathrm{VO} 2$ than the 1.5 -ventricle repair $(1.5 \mathrm{~V})$ group. The $1.5 \mathrm{~V}$ group also achieved a higher max heart rate than the UV repair group. *Overall $P$ value not significant; $\dagger$ Overall $P<.05 ; \alpha=P<.01$ compared with the reference group (ie, $1.5 \mathrm{~V}$-repair group); $\ddagger P<.05$ compared with reference group (ie, $1.5 \mathrm{~V}$-repair group).

\section{DISCUSSION}

Exercise Testing Results Following Repair of PAIVS: The Importance of Initial Tricuspid Valve $z$-Score

We have shown that late measures of aerobic capacity (eg, peak VO2) and chronotropic competence (eg, maximum heart rate) are lower in late survivors with PAIVS than in normal control subjects, regardless of the type of PAIVS repair achieved. Although our previous study concluded that ITVZ is an important determinant of survival and end state achievement, ${ }^{2}$ these results provide further support for clinical use of ITVZ (a discrete morphologic measure that is
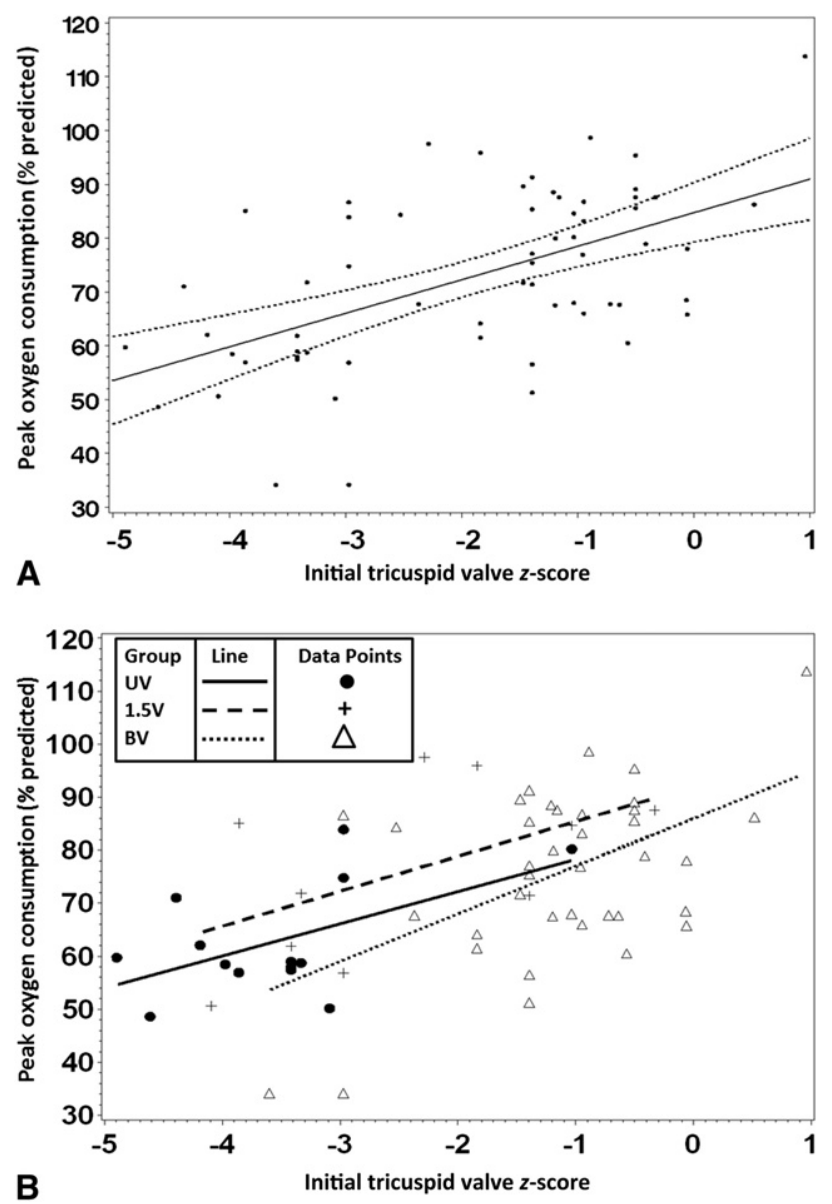

FIGURE 3. A, Percent predicted late peak oxygen consumption (VO2) across the spectrum of initial tricuspid valve $z$-scores for all participants. Peak VO2 increased linearly with increasing initial tricuspid valve $z$-score for all participants $(P<.001)$. Solid line is a best-fit regression lines enclosed by $95 \%$ confidence limits. Individual dots represent individual data points. B, Percent predicted late peak VO2 among the 3 end state groups over the range of initial tricuspid valve $z$-scores with riskadjusted best-fit regression lines for each group. Peak VO2 was higher for those with larger initial tricuspid valve $z$-score for all end state groups $(P<.001)$. It appears that biventricular $(B V)$ repair in patients with the highest values of initial tricuspid valve $z$-score $(>0)$ was associated with higher peak VO2 than was observed in other treatment groups. This is based on a very small number of patients in the BV group with initial tricuspid valve $z$-score values higher than all patients in the other treatment groups. Importantly, peak VO2 in the BV group with low initial tricuspid valve $z$-scores $(\mathrm{eg},<-2)$ tended to be lower than peak VO2 in the 1.5 -ventricle-repair group with comparable initial tricuspid valve $z$-scores.

readily available at initial presentation) in surgical decision making by exposing a relation to late peak VO2. In addition to increased risk of death, patients with more severe degrees of initial right heart hypoplasia who are forced down a BV pathway also incur greater risk of late deficits in aerobic capacity. Although we were not able to determine an absolute threshold at which a UV repair is preferable to a BV repair, our results are provocative and question the current wisdom 
that a BV strategy results in superior late objective performance. Sanghavi and colleagues ${ }^{13}$ compared exercise test results of patients with PAIVS repaired by either BV$(\mathrm{n}=19)$ or UV- repair strategies $(\mathrm{n}=10)$. Similar to our findings, they observed that patients who had undergone UV or BV repairs had subnormal aerobic capacity and overall peak VO2 did not vary between these repair types. However, chronotropic function was significantly better in the latter group, whereas we observed a trend favoring better chronotropic response in patients undergoing $1.5 \mathrm{~V}$-repair. In another recent report by Romeih and colleagues, ${ }^{14} 16$ patients (7 UV, $7 \mathrm{BV}$, and $21.5 \mathrm{~V}$ ) underwent comprehensive exercise testing and myocardial perfusion studies. The UV-repair group had significantly reduced exercise capacity, whereas the BV-repair group had normal exercise test results. With dobutamine stress imaging, left ventricular stroke volume increased only in the BV-repair group, and the UV-repair group exhibited significant chronotropic insufficiency. Results for their 1.5V-repair group were similar to those of their UV-repair group. These results are concordant with our univariable analysis, but are discordant following risk adjustment for other important variables such as the ITVZ, whereby the BV-repair group performed significantly worse.

Patients who had achieved 1.5V repair had higher peak $\mathrm{VO} 2$ values over the same range of ITVZ compared with patients undergoing BV repair, and also tended to achieve higher maximum heart rates. This has an important physiologic correlate in that, for some patients with smaller initial ITVZ, it is plausible that the addition of a cavopulmonary connection to antegrade flow through the RV outflow tract might supplement cardiac output, thereby increasing late exercise test results. One might also speculate that patients with $1.5 \mathrm{~V}$ repairs may incur less injury to the sinoatrial node due to lower risk of pressure elevation and surgical trauma. One caveat, however, is that small improvements in aerobic capacity and chronotropic response within the $1.5 \mathrm{~V}$-repair group were not accompanied by enhanced self-perceived FHS. Unfortunately, there are no studies that have examined both exercise testing and FHS concurrently within patients undergoing $1.5 \mathrm{~V}$ repair. Numata and colleagues ${ }^{15}$ performed exercise testing in 3 of 13 patients who underwent $1.5 \mathrm{~V}$ repairs for functional PAIVS. They concluded that in that small group, exercise test results were equivalent to a group of 26 Fontan patients with tricuspid atresia. The small numbers from this study and the lack of a true anatomic comparison group undergoing both UV and BV repair make inferences relative to our study difficult. Certainly, further studies directed at late outcomes in the $1.5 \mathrm{~V}$-repair group are needed given the findings from our current investigation.

Interestingly, our study demonstrated that ITVZ score was positively correlated with peak $\mathrm{VO} 2$ even in the UV-repair group. Influence of a structure in the nonsystemic ventricle was also demonstrated in the CHSS critical left ventricular outflow tract obstruction cohort study, whereupon small mitral valve $z$-score was predictive of death in UV-repair patients, but not in BV-repair patients. ${ }^{16}$ The association of greater right-sided hypoplasia with a higher prevalence of $\mathrm{RV}$-dependent coronary circulation is 1 possible explanation for our findings. Although it is true that we did not find a high prevalence of RV-dependent coronary circulation in this cohort, the number of patients was perhaps insufficient along the spectrum of severe tricuspid valve hypoplasia to exclude this as a possibility. For example, in the participating cohort, the median ITVZ score was -1.8 ; in the initial cohort it was -2.2 . Similarly, in the participating cohort there was only $1 \%$ prevalence of RV-dependent coronary circulation compared with $8 \%$ in the initial cohort. It has also been suggested by Tanoue and colleagues ${ }^{17}$ that a small, hypertensive RV may impair left ventricular performance after UV repair. Another potential explanation is that small ITVZ score is correlated with other harmful effects, including an increased number of interventions or operations, remaining in a palliated state with volume overload or cyanosis, or younger age at surgery, which could influence late exercise capacity in a manner we have not currently measured. Finally, ventricular interdependence in the context of very large RV volumes may impede left ventricular function, but it is plausible that a more modest degree of RV enlargement may not have the same detrimental effects vis-à-vis septal shift.

\section{FHS Outcomes Following Repair of PAIVS}

We found that patients with PAIVS scored lower than age- and sex-matched normal controls, but they performed better in nearly all psychosocial and relationship domains. Such evidence is important because it demonstrates, especially when coupled with EC data, that patients with PAIVS patients believe they are doing well despite their important physical impediments. In other words, there is a discrepancy between the subjective self-perception and the objective metrics of performance among our cohort of repaired survivors with PAIVS.

\section{Significance of This Study}

The multifactorial determinants of definitive end states in neonates with PAIVS, including mortality (pre- and postrepair) and achievement of complete repair, have been previously described. ${ }^{1,2,18-22}$ However, improved survival beyond complete repair in the contemporary era (to nearly $98 \%$ at age 7 years in 1 study $^{22}$ ) has refocused attention on other important outcome measures, such as FHS and long-term quality of life. Assessment of these outcomes are particularly important for patients with PAIVS for several reasons: (1) the wide morphologic spectrum enables a range of repair options, (2) a significant degree of morphologic overlap or gray zone exists in which evidence-based 
treatment selection are debated, and (3) a bias exists favoring $\mathrm{BV}$ repair in the absence of clear supporting evidence. Although prior reports have described FHS outcomes among patients with congenital heart disease, ${ }^{4,8,23-28}$ these studies have relied on comparisons to healthy subjects. Our study is unique in that it provides 3 diagnosisconcordant and concurrently obtained comparison groups (BV-, UV-, and 1.5V-repair groups), rather than relying solely on healthy children as controls.

\section{Relationship Between Performance Scores}

We found modest positive correlation between exercise testing measures and FHS scores (Appendix E2), although stronger than those associations reported in recent publications. ${ }^{6,8,24}$ The CHQ had the best correlation among the 3 questionnaires studied, suggesting that this may be the optimum instrument to evaluate FHS within PAIVS, given the implicit limitation of comparing an objective measurement to a subjective or self-perceived measurement. Improved instrument performance may be due to the comprehensive nature of the CHQ (87 questions) relative to the PedsQL (23 questions), or the CHAT (45 questions), or to enhanced discrimination within domains related to physical functioning.

\section{Noncardiac Factors Associated With Performance Measures}

Although the major focus of our investigation was to determine the relationship of initial morphologic factors and end states on late FHS, we anticipated based on previous data $^{5,8,23-35}$ and an unpublished report by Kulik and colleagues that noncardiac factors might contribute to these outcomes. McCrindle and colleagues ${ }^{5,8}$ found in a cross-sectional evaluation of Fontan patients that noncardiac medical conditions and psychosocial factors were likely to be more important factors associated with FHS than objective measurements of cardiopulmonary function. Similarly, Culbert and colleagues ${ }^{24}$ reported that the percent variation in CHQ scores explained by cardiac factors was small $\left(R^{2}, 0.02-0.26\right)$ among 306 patients following repair of transposition of the great arteries. In our study, we determined that socioeconomic status was associated with both exercise testing measures and FHS scores, and explained a considerable amount of the variation in scores. These results highlight the importance of comprehensive rehabilitation programs designed to address not only a patient's cardiac conditions and its sequelae, but his/her psychosocial environment and perceptions.

\section{Limitations}

Although functional assessment was performed prospectively, we cannot exclude selection or ascertainment bias as a confounder given that not all eligible survivors participated in the cross-sectional evaluation. That responders were generally similar to nonresponders, however, limits this source of bias. Missing data in potentially important variables, including the status of the atrial septum and whether or not peak effort was achieved on exercise testing, may have influenced our findings. The current focus on effort-independent submaximal indices may offer more useful information in children and adolescents than peak VO2. Not all patients completed both exercise testing and FHS tests, which limited the available data as well. Furthermore, the lack of concomitant echocardiography or supplemental medical information precludes the integration of our measured outcomes with individual clinical context. We acknowledge the subjectivity inherent to all functional health status instruments, although the use of 3 separate and widely validated questionnaires somewhat mitigates this limitation. Finally, the comparison to normal subjects' data (although a minor component of this study) must be tempered by the knowledge that subtle differences may exist between the normative data utilized and our population. The $z$-scores calculated in our study were derived from the pathologic study of Rowlatt and colleagues, ${ }^{12}$ which utilized formalin-fixed heart specimens. Given that all cardiac structures are known to shrink during the fixation process, these $z$-scores will result in larger numbers than $z$-scores calculated based on echocardiographic normative data. ${ }^{36}$ We chose to use Rowlatt's data, recognizing these limitations, to maintain consistency with prior CHSS publications involving this cohort. ${ }^{1,2}$

\section{CONCLUSIONS}

Late patient-perceived physical FHS and measured EC are reduced, regardless of PAIVS repair pathway, with an important dichotomy whereby PAIVS patients believe (based on improved psychosocial FHS scores relative to normal controls) they are doing well despite significant physical impediments. For selected patients with borderline degrees of right-sided hypoplasia (ie, those patients who do not meet clear criteria for either BV or UV repair), selection of a BV repair may result in reduced late EC. The addition of a cavopulmonary connection may represent a viable surgical option in this setting given its association with improved late aerobic and chronotropic function. Conversely, patients with more severe initial right-sided hypoplasia managed with BV repairs will likely have reduced late aerobic capacity. These findings underscore the need for a balanced approach to repair of PAIVS. In addition, our study emphasizes the clinical utility of ITVZ as an important determinant not only of survival and achievement of definitive repair, but also of late aerobic capacity and FHS.

\section{References}

1. Hanley FL, Sade RM, Blackstone EH, Kirklin JW, Freedom RM, Nanda NC. Outcomes in neonatal pulmonary atresia with intact ventricular septum. A multiinstitutional study. J Thorac Cardiovasc Surg. 1993;105:406-27. 
2. Ashburn DA, Blackstone EH, Wells WJ, Jonas RA, Pigula FA, Manning PB, et al. Determinants of mortality and type of repair in neonates with pulmonary atresia and intact ventricular septum. J Thorac Cardiovasc Surg. 2004;127:1000-8.

3. Paridon SM, Mitchell PD, Blafoux A, Gallagher D, Li J, Mital S, et al. A crosssectional study of exercise performance during the first two decades of life following the Fontan procedure. J Am Coll Cardiol. 2008;52:99-107.

4. McCrindle BW, Williams RV, Mitchell PD, Hsu DT, Paridon SM, Atz AM, et al. Relationship of patient and medical characteristics to health status in children and adolescents after the Fontan procedure. Circulation. 2006;113:1123-9.

5. Sleeper LA, Anderson P, Hsu DT, Mahony L, McCrindle BW, Roth SJ, et al. Design of a large cross-sectional study to facilitate future clinical trials in children with the Fontan palliation. Am Heart J. 2006;152:427-33.

6. McCrindle BW, Zak V, Sleeper LA, Paridon SM, Colan SD, Geva T, et al. Laboratory measures of exercise capacity and ventricular characteristics and function are weakly associated with functional status after Fontan procedure. Circulation. 2010;121:34-42.

7. Mahony L, Sleeper LA, Anderson PA, Gersony WM, McCrindle BW, Minich LL, et al. The Pediatric Heart Network: a primer for the conduct of multicenter studies in children with congenital heart disease. Pediatr Cardiol. 2006; 27:191-8.

8. McCrindle BW, Williams RV, Mitchell PD, Hsu DT, Paridon SM, Atz AM, et al. Relationship of patient and medical characteristics in health status in children and adolescents after the Fontan procedure. Circulation. 2006;113:1123-9.

9. Paridon SM. Exercise testing. In: Garson A, Bricker JT, Fisher DJ, Neish SR, eds. The science and practice of pediatric cardiology. 2 nd ed. Philadelphia: Williams \& Wilkins; 1998:875-88.

10. Hollingshead A. Four factor index of social status. New Haven: Yale University; 1975.

11. Gottfried AW. Measures of socioeconomic status in child development research: data and recommendations. Merrill Palmer Q. 1985;31:85-92.

12. Rowlatt UF, Rimoldi HJA, Lev M. The quantitative anatomy of the normal child's heart. Pediatr Clin North Am. 1963;10:499-588.

13. Romeih S, Groenink M, Roest AA, van der Plas MN, Hazekamp MG, Mulder BJ, et al. Exercise capacity and cardiac reserve in children and adolescents with corrected pulmonary atresia with intact ventricular septum after univentricular palliation and biventricular repair. J Thorac Cardiovasc Surg. 2012;143:569-75.

14. Sanghavi DM, Flanagan M, Powell AJ, et al. Determinants of exercise function following univentricular versus biventricular repair for pulmonary atresia/intact ventricular septum. Am J Cardiol. 2006;97:1638-43.

15. Numata S, Uemura H, Yagihara T, Kagisaki K, Takahashi M, Ohuchi H. Longterm functional results of the one and one half ventricular repair for the spectrum of patients with pulmonary atresia/stenosis with intact ventricular septum. Eur J Cardiothorac Surg. 2003;24:516-20.

16. Hickey EJ, Caldarone CA, Blackstone EH, Lofland GK, Yeh T Jr, Pizarro C, et al. Critical left ventricular outflow tract obstruction: the disproportionate impact of biventricular repair in borderline cases. J Thorac Cardiovasc Surg. 2007;134: 1429-37.

17. Tanoue Y, Kado H, Maeda T, Shiokawa Y, Fusazaki N, Ishikawa S. Left ventricular performance of pulmonary atresia with intact ventricular septum after right heart bypass surgery. $J$ Thorac Cardiovasc Surg. 2001;128:710-7.

18. Dyamenahalli U, McCRindle BW, McDonald C, Trivedi KR, Smallhorn JF, Benson LN, et al. Pulmonary atresia with intact ventricular septum: management of, and outcomes for, a cohort of 210 consecutive patients. Cardiol Young. 2004; 14:299-308.

19. Daubeney PEF, Wang D, Delany DJ, Keeton BR, Anderson RH, Slavik Z, et al. Pulmonary atresia with intact ventricular septum: predictors of early and medium-term outcome in a population-based study. J Thorac Cardiovasc Surg. 2005;130:1071-8.

20. Huang SC, Ishino K, Kasahara S, Yoshizumi K, Kotani Y, Sano S. The potential of disproportionate growth of tricuspid valve after decompression of the right ventricle in patients with pulmonary atresia and intact ventricular septa. J Thorac Cardiovasc Surg. 2009;138:1160-6.

21. Guleserian KG, Armsby LB, Thiagarajan RR, del Nido PJ, Mayer JE. Natural history of pulmonary atresia with intact ventricular septum and right ventricledependent coronary circulation managed by the single-ventricle approach. Ann Thorac Surg. 2006;81:2250-8.

22. Jahangiri M, Zurakowski D, Bichell D, Nayer JE, del Nido PJ, Jonas RA. Improved results with selective management in pulmonary atresia with intact ventricular septum. J Thorac Cardiovasc Surg. 1999;118:1046-55.

23. Kendall L, Lewin RJ, Parsons HM, Veldtman GR, Quirk J, Hardman GE. Factors associated with self-perceived state of health in adolescents with congenital cardiac disease attending paediatric cardiologic clinics. Cardiol Young. 2001 11:431-8.

24. Culbert EL, Ashburn DA, Cullen-Dean G, Joseph JA, Williams WG, Blackstone EH, et al. Quality of life of children after repair of transposition of the great arteries. Circulation. 2003;108:857-62.

25. Larsen SH, McCrindle BW, Jacobsen EB, Johnsen SP, Emmertsen K, Hjortdal VE. Functional health status in children following surgery for congenital heart disease: a population-based cohort study. Cardiol Young. 2010;20:631-40.

26. Moons P, De Bleser L, Budts W, Sluysmans T, De Wolf D, Massin N, et al. Functional status, functional abilities, and quality of life after the Mustard or Senning operation. Ann Thorac Surg. 2004;77:1359-65.

27. Gewillig MH, Lundstrom UR, Bull C, Wyse RK, Deanfield JE. Exercise responses in patients with congenital heart disease after Fontan repair: patterns and determinants of performance. J Am Coll Cardiol. 1990;15:1424-32.

28. Hager A, Hess J. Comparison of health related quality of life with cardiopulmonary exercise testing in adolescents and adults with congenital heart disease. Heart. 2005;91:517-20

29. Landgraf JM, Abetz L, Ware JE. The CHQ user's manual. 2nd ed. Boston: Health Act; 1999.

30. Landgraf JM, Abetz L, Ware JE Jr. Child health questionnaire. Boston: The Health Institute, New England Medical Center; 2008.

31. Waters EB, Salmon LA, Wake M, Wright M, Hesketh KD. The health and wellbeing of adolescents: a school-based population study of the self-report Child Health Questionnaire. J Adolesc Health. 2001;29:140-9.

32. Marino BS, Tomlinson RS, Wernovsky G, Drotar D, Newburger JW, Mahony L, et al. Validation of the pediatric quality of life inventory. Pediatrics. 2010;126: 498-508.

33. Gaies MG, Watnick CS, Gurney JG, Fl Bove, Goldberg CS. Health-related quality of life in patients with congenitally corrected transposition of the great arteries. J Thorac Cardiovasc Surg. 2011;142:136-41.

34. Varni JW, Seid M, Kurtin PS. PedsQL 4.0: reliability and validity of the Pediatric Quality of Life Inventory version 4.0 generic core scales in healthy and patient populations. Med Care. 2001;39:800-12.

35. Loonen HJ, Grootenhuis MA, Last BF, Koopman HM, Derkx HHF. Quality of life in paediatric inflammatory bowel disease measured by a generic and a disease-specific questionnaire. Acta Paediatr. 2002;91:348-54.

36. Kaski JP, Daubeney PEF. Normalization of echocardiographically derived paediatric cardiac dimensions to body surface area: time for a standardized approach Eur J Echocardiogr. 2009;10:44-5.

\section{Discussion}

Dr V. Mohan Reddy (Stanford, Calif). This study primarily sought to evaluate the effect of a strategy of repair on late functional outcomes and exercise capacity, especially to see if the biventricular strategy was superior to the single-ventricle or 1.5 -ventricle repair strategy. Despite the limitation that only $39 \%$ of the survivors participated in the study and only $63 \%$ to $77 \%$ completed all the tests, the study provides important inferences and is definitely a major contribution to the field.

The major strength in these 3 groups-namely, the biventricular, 1.5-ventricle, and single-ventricle groups-is that they are diagnosis-concordant and that the initial strategy of surgical repair is based on sound principles. It also appears that forcing biventricular repair in patients with lower $z$-scores reflects our obsession with 2-ventricle repairs, and perhaps this data will compel us to rethink that strategy. Having said that, I have several questions. First, were there enough patients in each group who completed all the tests? If so, did you analyze them separately?

Dr Karamlou. That's a very important question, as was the initial question, which was to determine if there is a tricuspid valve cutpoint that can guide all of our clinical decision making. Unfortunately, we were not able to determine a definitive cutpoint based on this study. I can tell you that if you look at the data and you 
segregate things, it looks like a tricuspid valve $z$-score of about -2 would give you a statistically significant difference between a univentricular repair on one hand and a biventricular repair on the other hand. But unfortunately, when you look at this as a continuum, we couldn't determine the threshold that you're seeking.

Dr Reddy. Thank you. The second question is: Within the biventricular group is there a cutoff of initial tricuspid valve $z$-score that predicted the functional capacity and the exercise capacity?

Dr Karamlou. That's an important question that we sought to answer and determine if there is a cutpoint that can guide all of our clinical decision making. Unfortunately, we were not able to determine a definitive cutpoint based on this study. I can tell you that if you look at the data and you segregate things, it looks like a tricuspid valve Z-score of about minus 2 would give you a statistically significant difference between a univentricular repair on one hand and a biventricular repair on the other hand. But unfortunately, when you look at this as a continuum, we couldn't determine the threshold that you're seeking.

Dr Reddy. Within the biventricular group did you see if presence or absence of atrial septal defect influenced functional and exercise capacity?

Dr Karamlou. Yes. Unfortunately, in this particular study we did not have echocardiographic information that was concomitant with all of the functional health status testing. That's something we hope to achieve in the future. So we didn't with absolute certainty know the status of the atrial septum. Now, if we knew it to be closed based on the yearly follow-up that the data center maintains on this cohort, we included that. But we cannot be certain that we know the status of the atrial septum contemporaneous with our evaluation.

Dr Reddy. That may be an important factor to see if having an atrial septal defect would increase enough cardiac output vis-à-vis the cavopulmonary shunt in 1.5 -ventricle repair patients.

Dr Karamlou. Yes, absolutely, I agree.

Dr Reddy. The next question to you is: How do you explain that the initial tricuspid valve size also correlated with peak oxygen uptake (VO2) even in patients with a single ventricle?

Dr Karamlou. We were perplexed initially by that relationship. But having looked at this retrospectively as well among our other cohorts, we saw essentially the same finding in the patients with critical aortic stenosis and aortic valve atresia, whereby the status of the mitral valve was influential in outcome even within patients who were triaged to a single-ventricle repair. So exactly the converse on the other side was true in that cohort.

Additionally, there are a couple of other things that one can speculate. One is that among other types of diagnoses there is ventricular interdependence and there is a ventricular interaction, so it could be that patients along the spectrum in the univentricular group with larger right ventricles - and therefore a large right ventricular mass - have some interaction with the systemic cardiac output, and that may influence their aerobic capacity. Second, perhaps the tricuspid valve $z$-score is surrogating other unfavorable or favorable anatomic characteristics like pulmonary arborization that unfortunately we could not look at.

Dr Reddy. I encourage you to add a paragraph to that effect in your discussion.

Dr Karamlou. Yes, that's a good point.
Dr Reddy. The next question: Peak VO2 was higher in 1.5-ventricle repair compared with biventricular repair regardless of the $z$-score, which suggests that tricuspid valve is not the only factor but right ventricle end-diastolic pressures or tricuspid insufficiency may be important and a cavopulmonary shunt might offset these factors. So my question based on this is: Should we consider the 1.5-ventricle option for patients with pulmonary atresia with intact ventricular septum, for all patients pulmonary atresia with intact ventricular septum, regardless of the initial tricuspid valve size?

Dr Karamlou. Yes, I think that question is anticipated based on these data, and I don't think what we're trying to convey is that for every anatomic subtype you should always do a 1.5 -ventricle repair. Again, we have to be circumspect. This was a small group of patients-only 14 in the 1.5-ventricle-repair group-and although statistically significant, the range of tricuspid valve $z$-scores on either side of those lines is small. There is a physiologic correlate to our findings in that patients with a 1.5 -ventricle strategy may be able to augment their cardiac output and therefore improve their aerobic capacity. But again, it's a small group of patients and warrants further study.

Dr Reddy. Do you plan to investigate any neurodevelopmentrelated outcomes in these 1.5 -ventricle group patients that might suggest that to increase the pressure in the superior vena cava may have some implications in developmental outcomes? That might offset recommending 1.5-ventricle repairs as opposed to just relying on peak VO2.

Dr Karamlou. I only presented the peak VO2 data in the interest of time. There are obviously comprehensive exercise variables that we plan to look at in a separate manuscript.

In terms of the neurodevelopment-related outcomes, although we could look at these data cross-sectionally, all would be confounded by not knowing what the patients started with initially. We know from data from Children's Hospital of Philadelphia that these patients start out with very different neurologic phenotypes that probably influence outcome. So although we could look at it late, I'm not sure we could make a strong conclusion.

Dr Reddy. It might simply show if there is any effect of increased superior vena cava pressure.

Dr Karamlou. That's true.

Dr Reddy. My last question is: We all know that tricuspid valve size changes as patients grow, depending upon various factorswhether or not there is the presence of ASD, because that might influence the amount of blood going across the tricuspid valve; what the right ventricle end-diastolic pressure is; and what the right ventricular function is. So if the tricuspid valve size is definitely influenced by growth, did you make any attempt to compare the exercise capacity outcomes vis-à-vis the current tricuspid valve $z$-score rather than the initial tricuspid valve $z$-score?

Dr Karamlou. Unfortunately we don't have the echocardiographic data contemporaneous with the exercise testing. So the thought of the current investigation was to correlate late functional health status with initial morphology. We don't really know what the tricuspid valve $z$-score in all patients is contemporaneous with the functional status or the exercise testing.

Dr Reddy. I think it's very relevant because it's important to know what the current size of the tricuspid valve is. And how it has grown compared to the original size. 
Dr Karamlou. Yes, absolutely. Another point to mention is that patients on a Fontan pathway may actually have a different trajectory than biventricular repair patients. Their course isn't static, and so getting the echo and other ancillary data about how the patients are doing clinically at the time of their functional status evaluation would give us additional context in which to interpret these results.

Dr John Foker (Minneapolis, Minn). It's important to have all the variables when you design a study. The main issues in these patients are right ventricular and tricuspid hypoplasia. So the important question and variable is the possibility of growth. It does not seem logical to decide to do a single or a biventricular repair if catch-up growth will erase the hypoplasia.

My question was going to be about growth; however, you have already discussed that you did not analyze how well the biventricular repairs grew or the difference in tricuspid valve scores with time. My group's previous research found that even a -4 tricuspid valve will grow up to normal size if you achieve total relief of right ventricular outflow obstruction, a restrictive atrial septal defect to encourage tricuspid valve flow yet maintain an adequate cardiac output, and ligation of all the important coronary artery fistulas or connections. My recommendation would be to have a growth arm in these studies in the future.

My final point is that some children with biventricular repairs will start to miss their pulmonary valve at about age 15 years. They may have reduced exercise capacity until somebody screws in a pulmonary valve. With a pulmonary valve in place these patient should have improved exercise capacity.

Dr Karamlou. Growth observation was actually in our initial grant application and for pragmatic purposes we chose to present the data we have. Certainly serial echocardiographic data are a critical component when studying this patient population.

Dr Charles Fraser (Houston, Tex). Would you speculate a little bit more about the subjective findings in these patients? To me that's the most encouraging thing that you presented. Although we want to make decisions using objective scientific data, if patients perceive themselves as doing well that's a very good thing. And it's fascinating.

I'll share a quick anecdote if I might. I just interviewed last week a 77-year-old woman who was operated on by Dr Blalock at age 5 years. She lived with a Blalock shunt for 50 years. She's had a wonderful life. She says "I love doctors." Her quality of life, from her perspective, was outstanding; from ours, she looked very disabled. What do you think about that and what can we learn from that going forward?

Dr Karamlou. It is very encouraging and important that there is a discrepancy between the subjective and the objective measures. Such a dichotomy has been seen in other studies; patients with congenital heart disease often believe they're doing better than control subjects. And it may be that there are multiple environmental factors. For example, it may be that people pay more attention to these patients as children. Psychosocial and emotional functioning is something we don't really understand and it's probably much more complex than putting somebody on a treadmill. Or, it may be that domains like bodily pain are calibrated differently. If you've experienced multiple operations, well, your idea of severe pain is probably different than somebody who has not undergone surgical procedures. It is fodder for additional studies. 


\section{APPENDIX E1. METHODS Inclusion Criteria}

A prior report from the Congenital Heart Surgeon's Society ${ }^{2}$ reported outcomes of 408 of these patients with pulmonary atresia with intact ventricular septum, whereupon atresia was defined as the absence of any antegrade flow through the native right ventricular outflow tract based on all available data. However, concurrent with this cohort were 40 additional patients with critical pulmonary stenosis followed annually by the data center. Consensus among the authors was to include these patients in the analysis for 2 reasons: comprehensive chart review of these patients revealed that 9 actually had atresia based on the aforementioned criteria, and the remaining 31 had discrepant findings regarding the status of the right ventricular outflow tract (ie, surgery revealed an imperforate valve, whereas cardiac catheterization or echocardiography demonstrated a trace of antegrade flow) and several of the critical pulmonary stenosis patients had clinical courses reminiscent of patients with pulmonary atresia with intact ventricular septum with severe right ventricular hypoplasia and right ventricular dependent coronary circulation in that they developed myocardial ischemia and hemodynamic instability with right ventricular decompression.

\section{Functional Health Status Instruments}

The Child Health Questionnaire (CHQ) was utilized in this study. The $\mathrm{CHQ}$ is a generic, but pediatric-specific, assessment tool to assess physical and psychosocial functional status of children between ages 5 and 18 years. $^{26,27}$ The child report form is composed of 87 items and has been validated for children aged 10 to 18 years. ${ }^{5,8,15}$ Domain scores are provided for the child report form (ie, summary scores are not available) to reflect physical functional status and psychosocial status (eg, emotional, behavioral, and social). Multiple prior publications from our group and others have utilized this instrument to assess functional status in patients following congenital heart surgery. ${ }^{5,8,15}$ The CHQ measures 11 child health concepts, with each being scored on a scale of 0 to 100 . Higher scores indicate better self-perceived function. Child report CHQ scores were converted to $z$-scores on the basis of published normative data. $^{28}$

The Pediatric Quality of Life Inventory (PedsQL) is a multi-item questionnaire assessing perceived functional health status (FHS) in children and adolescents aged 2 to 25 years. ${ }^{29-31}$ The 23-item PedsQL 4.0 Generic Core Scales assess physical (8 items), emotional (5 items), social (5 items), and school functioning ( 5 items). Separate self-report and parent-proxy forms exist for ages 5 to 7 years, 8 to 12 years, and 13 to 18 years. A young adult self-report form is available for patients aged 18 to 25 years. This study utilized the teen report form for patients aged 13 to 18 years, and the young adult form for patients aged 18 to 25 years. All items use a 5-point Likert scale designed to assess quality of life and level of functioning. Respondents report how often they experience specific problems grouped by functional domain $(0=$ never a problem, $1=$ almost never, $2=$ sometimes, $3=$ often, and $4=$ almost always a problem). Items are reverse-scored and linearly transformed to a scale from 0 to 100 , with 100 representing no problems within a functional domain and therefore the highest possible score. The emotional, social, and school functioning scores can be combined and averaged to generate a psychosocial health summary score. PedsQL scores were converted to $z$-scores on the basis of published normative data. $^{31}$

The Congenital Heart Adolescent and Teenager Questionnaire (CHAT) represents a congenital heart disease-specific FHS instrument designed for pediatric patients with congenital heart disease between ages 10 and 18 years. ${ }^{32-34}$ The preliminary version of the CHAT was developed by Kendall and colleagues ${ }^{23}$ after interviewing 37 adolescents with congenital heart disease regarding health-related concerns and self-perceived functional status. The questionnaire was then modified and piloted by Kulik and colleagues (unpublished data, 2006) within an outpatient cardiology clinic. Domains include the effects of congenital heart disease on general health, perceived seriousness of heart condition, symptoms/discomforts, activity limitations, effects on social life, emotional problems, friendship problems, and effect on career/education. Lower scores in CHAT domains represent higher FHS. The CHAT was used in this study because it provides an assessment of FHS that is disease- and age-specific for patients with congenital heart disease.

\section{APPENDIX E2. RESULTS \\ Correlation Between Exercise Test Measures And Functional Status Questionnaires}

The percent variation in peak oxygen consumption (VO2) accounted for by Child Health Questionnaire (CHQ) domain scores was $56 \%\left(R^{2}, 0.56\right)$, with higher peak VO2 significantly related to higher physical functioning $z$-score (parameter estimate $0.06 \pm 0.03 ; P=.058$ ). Similarly, the percent variation in maximum heart rate explained by the cumulative CHQ domain scores was $47 \%$ $\left(R^{2}, 0.47\right)$, with higher maximum heart rate associated with higher physical functioning $z$-score (parameter estimate $0.05 \pm 0.03 ; P=.07$ ). The percent variation in both peak VO2 and maximum heart rate explained by the Pediatric Quality of Life Inventory (PedsQL) summary scores (4\% and $13 \%$, respectively) and the Congenital Heart Adolescent and Teenager Questionnaire (CHAT) (17\% and $18 \%$, respectively) was much lower, with no significant associations detected. Peak VO2 scores were weakly correlated with physical functioning $(R, 0.35 ; P=.02)$ and global health domains $(R, 0.29 ; P=.06)$ in the CHQ, and with the friends $(R,-0.32 ; P=.04)$ and emotions domains in the CHAT $(R,-0.33 ; P=.04)$. Maximum heart rate scores were weakly correlated with global health $(R, 0.37$; $P=.01)$, physical functioning $(R, 0.42 ; P=.004)$, bodily pain $(R, 0.36 ; P=.048)$, and general health perceptions $(R, 0.39 ; P=.008)$ in the CHQ. Maximum heart rate scores were also weakly correlated with the physical functioning domain in the PedsQL $(R, 0.37 ; P=.01)$ and with the activity $(R,-0.33 ; P=.03)$ and discomfort domains $(R,-0.22$; $P=.05)$ in the CHAT. Importantly, patients in the 1.5 -ventricle repair group achieved greater maximum heart rates than the biventricle repair group, yet had reported lower measures of functional health status (Figure 2, $A$ and $B$ ). 


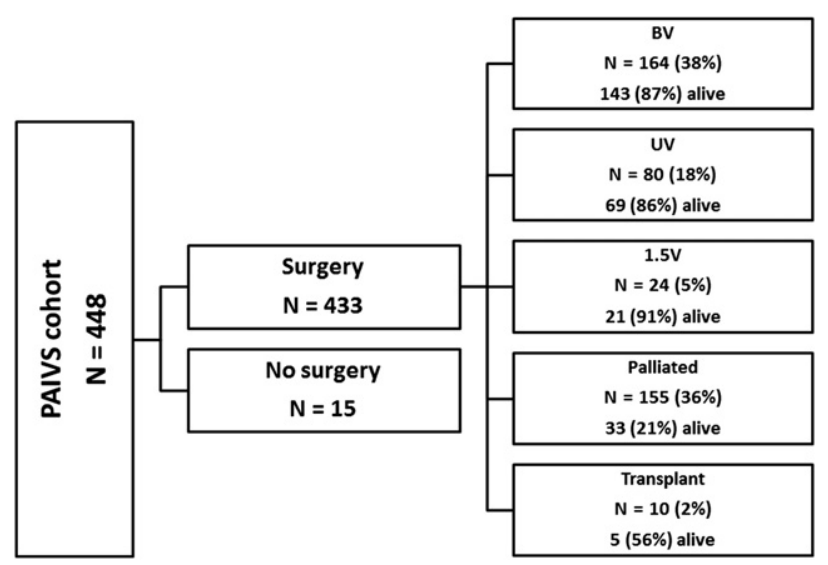

FIGURE E1. Flowchart depicting the final end states and survival among the entire cohort of patients with pulmonary atresia with intact ventricular septum (PAIVS). BV, Biventricular repair; $U V$, univentricular repair; $1.5 \mathrm{~V}, 1.5$-ventricle repair.
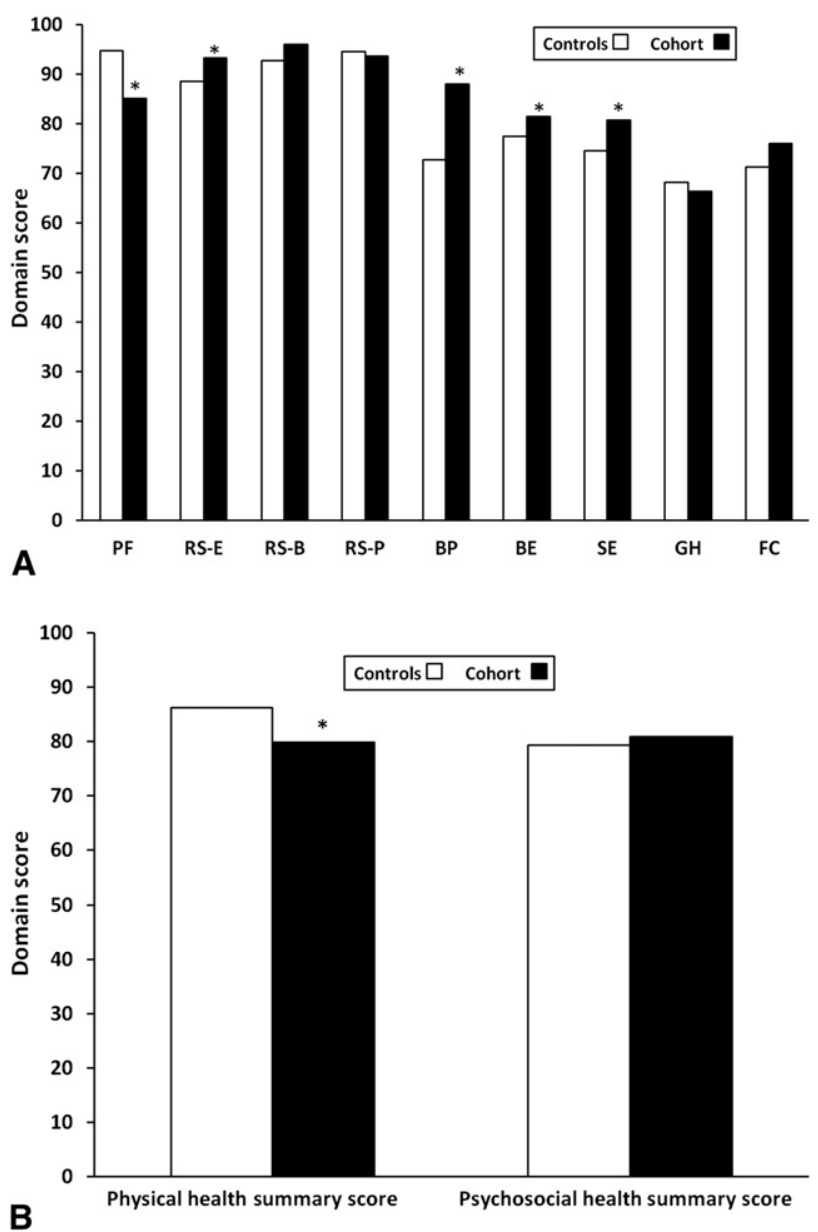

FIGURE E2. A, Histograms demonstrating functional health status results obtained from the Child Health Questionnaire $(\mathrm{CHQ})$ for all participants with pulmonary atresia with intact ventricular septum (PAIVS) compared with age- and sex-matched normal controls. Participants scored lower than age- and sex-matched normal controls in physical functioning, but they performed better in psychosocial and relationship domains. Such evidence is important because it demonstrates that patients with PAIVS believe they are doing well despite their important physical impediments. B, Histograms demonstrating functional health status results obtained from the Pediatric Quality of Life Inventory 4.0 (PedsQL) for patients with PAIVS compared with age- and sex-matched normal controls. Concordant with the CHQ, participants with PAIVS scored lower in domains of physical functioning compared with normal control subjects, but were equivalent in psychosocial domains. $P F$, Physical functioning; $R S-E$, role social-emotional; $R S$ - $B$, role social behavioral; $B P$, bodily pain; $B E$, behavioral; $S E$, self-esteem; $G H$, general health; $F C$, family cohesion. $* P \leq .05$. 


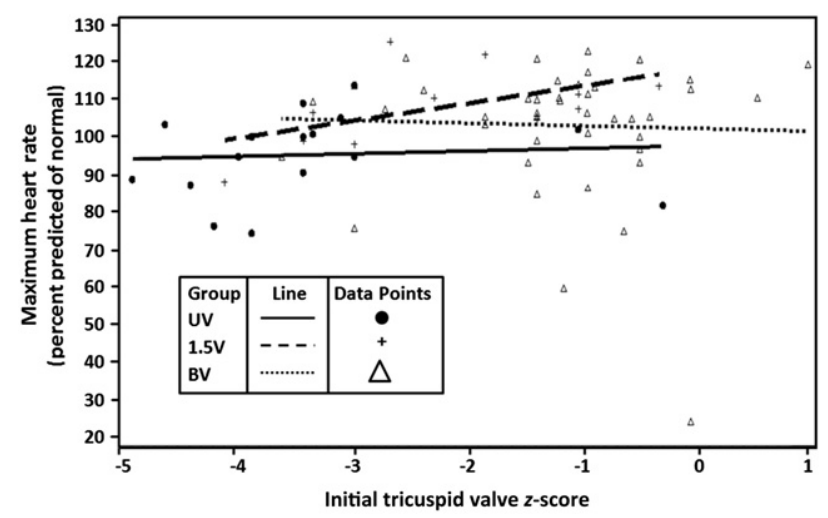

FIGURE E3. Percent predicted late maximum heart rate among the 3 end state groups over the range of initial tricuspid valve $z$-scores with riskadjusted best-fit regression lines for each group. Although the 1.5ventricle $(1.5 \mathrm{~V})$ repair group achieved higher maximum heart rate than the biventricular $(B V)$ repair group, there was no influence of initial tricuspid valve $z$-score. $U V$, Univentricular.

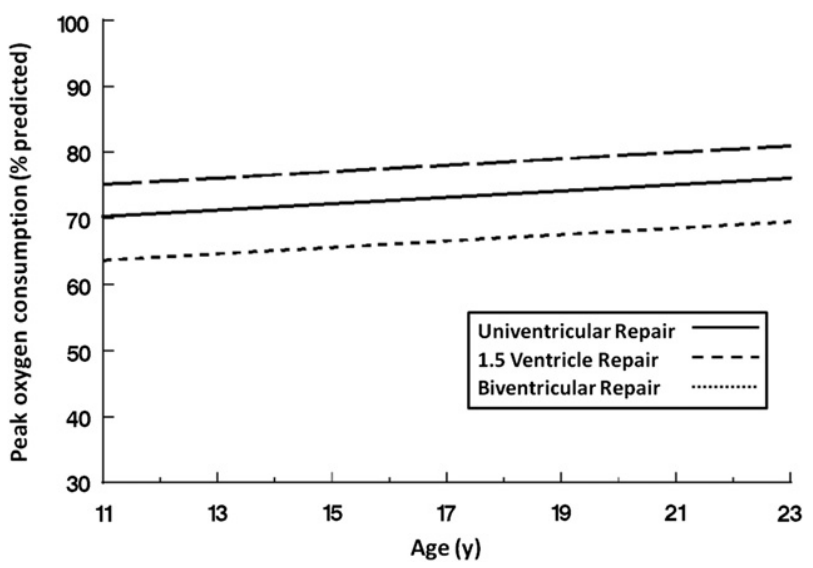

FIGURE E4. Risk-adjusted nomogram of peak oxygen consumption (VO2) across the range of participant ages demonstrates 3 solutions for the multivariable peak VO2 equation for a hypothetical male patient with an initial tricuspid valve $z$-score of -2 . Although peak VO2 increases with increasing age in all end state groups, the 1.5-ventricle repair group had improved peak VO2 compared with both the biventricular-repair and univentricular-repair groups, although this difference was significant only between the 1.5-ventricle-repair group and biventricular-repair group.
TABLE E1. Independent factors associated with exercise test variables and selected functional health status domains

\begin{tabular}{lcc}
\hline \multirow{2}{*}{\multicolumn{1}{c}{ Variable }} & \multicolumn{2}{c}{ VO2 } \\
\cline { 2 - 3 } & Estimate \pm SE & $\boldsymbol{P}$ value \\
\hline Age at evaluation $(\mathrm{y})$ & $0.002 \pm 0.02$ & .80 \\
Boys & $-0.04 \pm 0.04$ & .35 \\
Univentricular end state & $-0.02 \pm 0.07$ & .11 \\
Biventricular end state & $-0.18 \pm 0.07$ & .02 \\
1.5 Ventricle end state & \multicolumn{2}{c}{ Reference group } \\
Tricuspid valve $z$-score & $0.11 \pm 0.02$ & $<.001$ \\
\hline
\end{tabular}

Age and sex included in all models as normalizing variables; other candidate variables tested but not found to be significant include number of procedures, interval from repair to evaluation, presence of atrial septal defect, right ventricular systolic pressure, and Hollingshead score. Model $R^{2}, 0.59$. VO2, Oxygen consumption; $S E$, standard error.

\begin{tabular}{lcc}
\hline \multirow{1}{*}{\multicolumn{1}{c}{ Variable }} & \multicolumn{2}{c}{ Maximum heart rate } \\
\cline { 2 - 3 } & Estimate $\pm \mathbf{S E}$ & $\boldsymbol{P}$ value \\
\hline Age at evaluation (y) & $0.01 \pm 0.01$ & .16 \\
Girls & $0.001 \pm 0.07$ & .98 \\
Univentricular end state & $-0.05 \pm 0.11$ & .64 \\
Biventricular end state & $-0.19 \pm 0.09$ & .06 \\
1.5 Ventricle end state & \multicolumn{2}{c}{ Reference group } \\
Tricuspid valve incompetence & $-0.25 \pm 0.12$ & .05 \\
Coronary-cameral fistulae & $-0.30 \pm 0.11$ & .01 \\
Hollingshead score & $0.007 \pm 0.003$ & .05 \\
\hline
\end{tabular}

Age and sex included in all models as normalizing variables; other candidate variables tested but not found to be significant include number of procedures, interval from repair to evaluation, presence of atrial septal defect, right ventricular systolic pressure, and tricuspid valve $z$-score. Model $R^{2}, 0.47$. SE, Standard error.

\begin{tabular}{lcc}
\hline \multirow{1}{*}{\multicolumn{1}{c}{ Variable }} & \multicolumn{2}{c}{ CHQ global health score } \\
\cline { 2 - 3 } & Estimate \pm SE & $\boldsymbol{P}$ value \\
\hline Age at evaluation $(\mathrm{y})$ & $-0.002 \pm 0.06$ & .98 \\
Girls & $0.40 \pm 0.30$ & .19 \\
Univentricular end state & $0.46 \pm 0.56$ & .42 \\
Biventricular end state & $0.28 \pm 0.49$ & .58 \\
1.5 Ventricle end state & \multicolumn{2}{c}{ Reference group } \\
> 5 procedures & $0.67 \pm 0.52$ & .20 \\
Coronary-cameral fistulae & $0.68 \pm 0.47$ & .15 \\
Hollingshead score & $0.03 \pm 0.02$ & .07 \\
\hline
\end{tabular}

Age and sex included in all models as normalizing variables; other candidate variables tested but not found to be significant include tricuspid valve incompetence, interval from repair to evaluation, presence of atrial septal defect, right ventricular systolic pressure, and tricuspid valve $z$-score. Model $R^{2}, 0.26$. CHQ, Child Health Questionnaire; $S E$, standard error.

\begin{tabular}{lcc}
\hline \multirow{2}{*}{ Variable } & \multicolumn{2}{c}{ CHQ role social physical functioning score } \\
\cline { 2 - 3 } & Estimate \pm SE & $\boldsymbol{P}$ value \\
\hline Age at evaluation $(\mathrm{y})$ & $-0.009 \pm 0.03$ & .77 \\
Girls & $0.03 \pm 0.19$ & .86 \\
Univentricular end state & $0.47 \pm 0.33$ & .15 \\
Biventricular end state & $0.79 \pm 0.29$ & .009 \\
1.5 Ventricle end state & \multicolumn{2}{c}{ Reference group } \\
Tricuspid valve z-score & $0.16 \pm 0.10$ & .09 \\
Age at repair (y) & $0.07 \pm 0.04$ & .11 \\
Hollingshead score & $0.02 \pm 0.01$ & .12 \\
\hline
\end{tabular}

Age and sex included in all models as normalizing variables; other candidate variables tested but not found to be significant include interval from repair to evaluation, presence of atrial septal defect, right ventricular systolic pressure, and right ventricular fistulae. Model $R^{2}, 0.13$. $C H Q$, Child Health Questionnaire; $S E$, standard error. 